\title{
Características de carcaça e da carne de caprinos Boer $x$ Saanen confinados recebendo rações com casca do grão de soja em substituição ao milho ${ }^{1}$
}

\section{Juliano Hideo Hashimoto ${ }^{2}$, Claudete Regina Alcalde ${ }^{3}$, Karina Toledo da Silva ${ }^{2}$, Francisco de Assis Fonseca de Macedo ${ }^{3}$, Alexandre Agostinho Mexia $^{2}$, Graziela Aparecida Santello², Elias Nunes Martins ${ }^{3}$, Makoto Matsushita ${ }^{4}$}

\footnotetext{
1 Parte da dissertação de Mestrado do primeiro autor apresentada à UEM.

2 Programa de Pós-Graduação em Zootecnia - UEM.

${ }^{3}$ Departamento de Zootecnia da Universidade Estadual de Maringá - UEM. Av. Colombo 5790, CEP: 87020-900, Maringá - PR.

${ }^{4}$ Departamento de Química da Universidade Estadual de Maringá - UEM.

* Bolsista CAPES.
}

RESUMO - Avaliaram-se as características de carcaça, os rendimentos dos cortes, a proporção dos tecidos, a composição química e o perfil de ácidos graxos do músculo Longissimus dorsi de cabritos confinados alimentados com rações contendo casca do grão de soja em substituição ao grão de milho moído. Foram utilizados 15 cabritos machos inteiros Boer $x$ Saanen distribuídos em delineamento inteiramente casualizado (cinco animais por tratamento) e abatidos com $33,82 \pm 4,40 \mathrm{~kg}$ de peso corporal. As rações foram compostas de feno de grama-estrela (Cynodon spp.), farelo de soja, milho moído e/ou casca do grão de soja e minerais. Os tratamentos foram constituídos de 0,50 e $100 \%$ de substituição do milho pela casca do grão de soja. Os níveis de substituição do milho pela casca do grão de soja não alteraram as características de carcaça, mas influenciaram o rendimento dos cortes comerciais do lombo e do pescoço. A porcentagem de carne do músculo Longissimus dorsi não foi afetada pelos tratamentos, entretanto, os animais do tratamento que não receberam casca do grão e soja apresentaram maiores proporções de gordura e menores de osso. A composição centesimal e o perfil dos ácidos graxos não diferiram entre os animais, contudo, o músculo Longissimus dorsi daqueles alimentados com casca do grão de soja apresentou maiores teores de colesterol. A casca do grão de soja pode ser utilizada como substituto do milho em rações, pois não alterou as características de carcaça e de carne dos animais.

Palavras-chave: ácidos graxos, alimentação, caprinos, colesterol, rendimento

\section{Characteristics of carcass and meat of feedlot Boer $x$ Saanen kids fed diets with ground corn replaced by soybean hulls}

\begin{abstract}
The objective of this trial was to evaluate carcass characteristics, cuts yield, tissues proportion, and chemical composition and fatty acid profile of the Longissimus dorsi of feedlot kids fed diets, in which soybean hulls (SH) replaced ground corn grain (GCG). Fifteen Boer x Saanen male kids were assigned to a completely randomized design (five animals per treatment) and slaughtered at $33.82 \pm 4.40 \mathrm{~kg}$ of body weight. Diets were composed by star grass hay (Cynodon spp), soybean meal, GCG and/or SH, and minerals. Ground corn grain was replaced by SH in the diet as follows: 0\% SH (GCG), 50\% (SH50) and 100\% (SH100). Carcass characteristics were not affected by the increasing levels of SH in the diet. However, yield of retail cuts from the loin and neck differed across treatments. Percentage of meat from the Longissimus dorsi muscle was not affected by increasing SH in the diet but kids fed GCG diet showed greater proportion of fat and lower of bone compared to SH50 and SH100 treatments. The chemical composition and the fatty acid profile of the Longissimus dorsi muscle were similar among treatments although its cholesterol content was greater when SH was included in the diet. Soybean hulls can replace GCG in the diet because no significant changes were observed in the characteristics of carcass and meat.
\end{abstract}

Key Words: cholesterol, carcass yield, fatty acid, feeding, goats

\section{Introdução}

No sistema de produção de carne, as características quantitativas da carcaça são fundamentais no processo produtivo, pois estão diretamente relacionadas ao produto final carne. O principal fator que confere valor à carcaça é o rendimento, que depende primeiramente do conteúdo do aparelho digestório, que pode variar de 8 a $18 \%$ do peso corporal de acordo com o nível de alimentação do animal (Sainz, 1996). Os valores de rendimento de carcaça em caprinos variam de 35 a $60 \%$ (Dhanda et al., 2003a; Sheridan et al., 2003; Pereira Filho, 2003; Silva, 2005, Ulhoa, 2001; 
Yáñez, 2002), dependendo da metodologia utilizada na sua determinação, observando-se que o rendimento verdadeiro, ou biológico, da carcaça é o mais preciso, pois elimina as variações do conteúdo digestivo em seu cálculo.

Das partes que compõem a carcaça, a de maior interesse ao consumidor é a carne. A análise da área do músculo Longissimus dorsi ou área de olho-de-lombo é considerada medida representativa da quantidade e distribuição, assim como da qualidade, das massas musculares. Os músculos de maturidade tardia são indicados para representar o índice mais confiável do desenvolvimento e tamanho do tecido muscular; assim, o Longissimus dorsi é o mais indicado, pois, além do amadurecimento tardio, é de fácil mensuração (Sainz, 1996).

Considerando que a carne é uma das maiores fontes de gordura da dieta, principalmente das gorduras saturadas, e tem sido associada a várias doenças, como cânceres e distúrbios cardiovasculares, o interesse em sua composição em ácidos graxos tem aumentado nos últimos anos, principalmente por pessoas interessadas em manter uma alimentação saudável.

Neste sentido, a carne caprina tem sido considerada um produto com alto potencial de expansão, em decorrência de sua composição. Quando comparada a outras carnes vermelhas, como a bovina e a ovina, apresenta quantidades semelhantes em proteína e ferro, porém, quantidades menores de gordura, o que resulta em menor proporção de gordura saturada e calorias (Malan, 2000), além de menores níveis de colesterol (Naudé \& Hofmeyr, 1981).

Ressalta-se que as propriedades físicas e químicas dos lipídeos afetam diretamente as qualidades nutricionais, sensoriais e de conservação da carne. Os ácidos graxos saturados solidificam após o cozimento, influenciando a palatabilidade da carne. Por outro lado, os insaturados aumentam o potencial de oxidação, influenciando diretamente a vida de prateleira da carne in natura ou cozida (Banskalieva et al., 2000; Wood et al., 2003). Além disso, recentes estudos têm comprovado que o perfil de ácidos graxos é a principal fonte do sabor característico de determinada espécie (Mottram, 1998; Madruga et al., 2001, 2003).

Em caprinos, tem-se demonstrado que o perfil dos ácidos graxos do tecido adiposo é influenciado pela dieta (Potchoiba et al., 1990; Rhee et al., 2000) e pela idade do animal (Zygoyiannis et al., 1992).

Neste estudo, objetivou-se avaliar as características de carcaça, os rendimentos dos cortes, a proporção dos tecidos, a composição química e o perfil de ácidos graxos do músculo Longissimus dorsi de cabritos Boer x Saanen confinados alimentados com rações contendo casca do grão de soja em substituição ao grão de milho moído.

\section{Material e Métodos}

O experimento foi conduzido no setor de Caprinocultura da Fazenda Experimental de Iguatemi (FEI), da Universidade Estadual de Maringá (UEM). Foram utilizados 15 cabritos machos inteiros Boer $\times$ Saanen $(28,29 \pm 2,71 \mathrm{~kg}$ de peso corporal e $132 \pm 5$ dias de idade) identificados e distribuídos aleatoriamente, perfazendo um total de cinco animais por tratamento. Por apresentar problemas de saúde, um animal do tratamento com $100 \%$ de grão de milho moído (GMM) foi retirado do experimento.

As rações foram compostas de feno de grama-estrela (Cynodon spp.), farelo de soja, milho moído e/ou casca do grão de soja e minerais, sendo formuladas com 0 (GMM), 50 (CGS50)e 100\% (CGS100) de substituição do milho pela casca do grão de soja. As rações foram ajustadas para se obter uma dieta com 2,63 Mcal de EM/kg MS e 17\% de PB (Tabelas 1 e 2).

Os animais foram mantidos em baias individuais cobertas (piso ripado e suspenso), equipadas com comedouros individuais e bebedouro para dois animais, com água à vontade. Ao atingirem $33,82 \pm 4,40 \mathrm{~kg}$ de peso corporal e $188 \pm 5$ dias de idade, os animais foram mantidos durante 18 horas sob dieta hídrica e abatidos.

Ao abate, os animais foram novamente pesados (peso corporal ao abate). $\mathrm{O}$ aparelho gastrintestinal foi esvaziado para obtenção do peso corporal vazio (o peso corporal ao abate menos o peso do conteúdo gastrintestinal) visando determinar o rendimento verdadeiro de carcaça, que é a relação entre o peso da carcaça quente e o peso corporal vazio (Sañudo \& Sierra, 1986).

Após a evisceração, as carcaças foram pesadas (peso da carcaça quente) e transferidas para câmara fria a $4^{\circ} \mathrm{C}$, onde foram mantidas por 24 horas, penduradas pelos tendões, em ganchos apropriados, para manutenção das articulações tarsometatarsianas distanciadas em $17 \mathrm{~cm}$.

Ao final das 24 horas, a carcaça fria foi retirada da câmara fria e pesada, sendo calculados, em porcentagem, a perda de peso por resfriamento e o rendimento comercial de carcaça, que é a relação entre o peso da carcaça fria e o peso corporal ao abate.

Foram realizadas as seguintes medidas: comprimento da perna - distância entre o períneo e o bordo anterior das superfícies articulares tarsometatarsianas; comprimento interno da carcaça - distância máxima entre o bordo anterior da sínfise ísquio-pubiana e o bordo anterior da primeira costela em seu ponto médio; largura da garupa - largura máxima entre os trocânteres de ambos os fêmures; índice de compacidade da carcaça - peso da carcaça fria dividido pelo comprimento interno da carcaça; e 
Tabela 1 - Composição químico-bromatológica e dos principais ácidos graxos dos alimentos utilizados Table 1 - Chemical composition and main fatty acids of the dietary ingredients

\begin{tabular}{|c|c|c|c|c|}
\hline \multirow[t]{2}{*}{$\begin{array}{l}\text { Nutriente } \\
\text { Nutrient }\end{array}$} & \multicolumn{4}{|c|}{$\begin{array}{l}\text { Alimento } \\
\text { Feed }\end{array}$} \\
\hline & $\begin{array}{l}\text { Grão de milho moído } \\
\text { Ground corn grain }\end{array}$ & $\begin{array}{c}\text { Farelo de soja } \\
\text { Soybean meal }\end{array}$ & $\begin{array}{c}\text { Casca do grão de soja } \\
\text { Soybean hulls }\end{array}$ & $\begin{array}{c}\text { Feno de grama-estrela } \\
\text { Stargrass hay }\end{array}$ \\
\hline $\operatorname{MS}(D M)(\%)$ & 89,85 & 90,50 & 92,60 & 92,77 \\
\hline $\mathrm{MO}(\% \mathrm{MS})(O M, \% D M)$ & 98,93 & 93,33 & 92,78 & 95,46 \\
\hline Cinzas (\%MS) (Ash, \%DM) & 1,07 & 6,67 & 7,22 & 4,54 \\
\hline $\mathrm{PB}(\% \mathrm{MS})(C P, \% D M)$ & 8,38 & 49,56 & 15,45 & 6,36 \\
\hline $\mathrm{EE}(\% \mathrm{MS})(E E, \% D M)$ & 3,59 & 2,10 & 2,43 & 1,00 \\
\hline FDN $(\% \mathrm{MS})(N D F, \% D M)$ & 12,34 & 14,85 & 60,74 & 79,75 \\
\hline FDA $(\% \mathrm{MS})(A D F, \% D M)$ & 3,81 & 10,32 & 46,81 & 43,30 \\
\hline Lignina (\%MS) (Lignin, \%DM) & 1,36 & 1,59 & 6,26 & 7,91 \\
\hline Celulose (\%MS) (Cellulose, \%DM) & 2,42 & 8,57 & 38,84 & 33,99 \\
\hline Amido (\% MS) (Starch, \%DM) & 73,11 & 1,22 & 0,14 & 1,37 \\
\hline \multicolumn{5}{|l|}{$\begin{array}{l}\text { Ácidos graxos } \\
\text { Fatty acids } \\
\end{array}$} \\
\hline C12:0 & - & - & - & 34,83 \\
\hline C14:0 & 0,17 & 0,18 & 0,51 & 1,91 \\
\hline C16:0 & 13,51 & 18,11 & 16,05 & 14,06 \\
\hline C18:0 & 2,30 & 3,91 & 6,12 & 2,11 \\
\hline C $18: 1 n-9$ & 33,58 & 16,91 & 18,57 & 3,91 \\
\hline C $18: 1 n-7$ & 1,26 & 2,04 & 1,17 & 0,56 \\
\hline C $18: 2 n-6$ & 46,89 & 54,50 & 38,01 & 6,11 \\
\hline C $18: 3 n-3$ & 0,78 & 4,07 & 6,29 & 4,37 \\
\hline$C 20: 3 n-9$ & - & - & 0,96 & 3,82 \\
\hline$C 20: 4 n-3$ & 1,40 & 0,18 & 1,06 & 1,36 \\
\hline$C 22: 6 n-3$ & - & - & 0,99 & 17,26 \\
\hline
\end{tabular}

Tabela 2 - Composição percentual e químico-bromatológica (\% MS) das rações experimentais Table 2 - Ingredient and chemical composition (\% DM) of the experimental diets

\begin{tabular}{|c|c|c|c|}
\hline & \multicolumn{3}{|c|}{$\begin{array}{c}\text { Tratamento } \\
\text { Diet }\end{array}$} \\
\hline & $\begin{array}{c}\text { GMM } \\
G C G \\
\end{array}$ & $\begin{array}{c}\text { CGS } 50 \\
\text { SH } 50\end{array}$ & $\begin{array}{c}\text { CGS } 100 \\
\text { SH } 100\end{array}$ \\
\hline Feno de grama-estrela (Stargrass hay) & 30,00 & 30,00 & 30,00 \\
\hline Farelo de soja (Soybean meal) & 19,83 & 17,83 & 15,77 \\
\hline Grão de milho moído (Ground corn grain) & 46,45 & 24,50 & - \\
\hline Casca do grão de soja (Soybean hulls) & - & 24,50 & 51,14 \\
\hline Fosfato bicálcico (Dicalcium phosphate) & 0,19 & 0,17 & 0,09 \\
\hline Calcário (Limestone) & 0,53 & - & - \\
\hline Suplemento mineral (Mineral supplement $)^{1}$ & 3,00 & 3,00 & 3,00 \\
\hline MS $(D M)(\%)$ & 91,12 & 91,74 & 92,45 \\
\hline MO $(O M)$ & 93,20 & 92,34 & 90,89 \\
\hline Cinzas (Ash) & 6,80 & 7,66 & 9,11 \\
\hline $\mathrm{PB}(C P)$ & 15,63 & 16,58 & 17,63 \\
\hline $\mathrm{EE}(E E)$ & 2,39 & 2,15 & 1,87 \\
\hline FDN $(N D F)$ & 32,60 & 44,48 & 57,33 \\
\hline FDA $(A D F)$ & 16,81 & 27,23 & 38,56 \\
\hline Lignina (Lignin) & 3,32 & 4,52 & 5,82 \\
\hline Celulose (Cellulose) & 13,02 & 21,83 & 31,41 \\
\hline Amido (Starch) & 34,61 & 18,58 & 0,68 \\
\hline EM $(\mathrm{Mcal} / \mathrm{kg}$ MS $)(M E, \text { Mcal } / \mathrm{kg} D M)^{3}$ & 2,54 & 2,37 & 2,13 \\
\hline \multicolumn{4}{|c|}{ 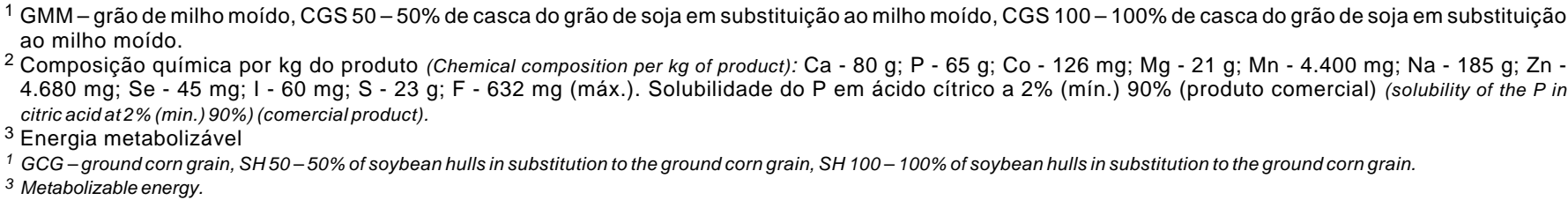 } \\
\hline
\end{tabular}


índice de compacidade da perna - largura da garupa dividida pelo comprimento da perna.

Foi realizada a avaliação visual, segundo metodologia de Colomer-Rocher et al. (1988): grau de conformação das carcaças - determinado pela avaliação visual da carcaça considerando-a como um todo, ponderando-se as diferentes regiões anatômicas da carcaça (perna, garupa, lombo e espádua), e da espessura de seus planos musculares e adiposos em relação ao tamanho do esqueleto que a suporta, sendo atribuídos valores 1,0 para conformação muito pobre e 5 para excelente; cobertura de gordura - 1,0 para excessivamente magra e 5 para excessivamente gorda. As notas referentes a estas avaliações foram subdivididas em intervalos de 0,5.

Posteriormente, as carcaças foram divididas longitudinalmente e a metade esquerda foi seccionada em sete regiões anatômicas, sendo pesadas individualmente para determinação de suas porcentagens em relação ao todo. Foram determinadas as seguintes regiões anatômicas: perna - conjunto que compreende as regiões glútea, femural e da perna, tendo como base óssea o tarso, a tíbia, o fêmur, o ísquio, o púbis e o ílio, separados por um corte perpendicular à coluna, entre a última vértebra lombar e a primeira sacra e na junta tarsometatarsiana; lombo - conjunto formado pelas vértebras lombares, sendo a zona que incide perpendicularmente à coluna, entre a 13a vértebra torácica e a última lombar; paleta - tem como base anatômica a escápula, o úmero, a ulna, o rádio e o carpo; costelas - oito últimas vértebras torácicas juntamente com a metade superior das costelas correspondentes; costelas descobertas - apresentam como base óssea as cinco primeiras vértebras torácicas, junto com a metade superior das costelas correspondentes; baixos - são obtidos traçando-se uma linha reta da borda dorsal do abdome à ponta do esterno; e pescoço - compreende a região anatômica das sete vértebras cervicais, sendo obtido por meio de um corte oblíquo entre a sétima vértebra cervical e a primeira torácica.

A demarcação do músculo Longissimus dorsi (entre a última vértebra torácica e a primeira lombar - lombo) foi realizada mediante o corte transversal do músculo, delineado com o uso de papel transparência e caneta própria. Em seguida, determinou-se a área de olho-de-lombo utilizando-se o programa computacional AUTOCAD ${ }^{\circledR}$.

Ainda no Longissimus dorsi, utilizando-se paquímetro, foram feitas quatro medidas: medida A - comprimento maior do músculo Longissimus dorsi, perpendicular ao eixo ou à medida $\mathrm{B}$; = medida $\mathrm{B}$ - comprimento menor, ou profundidade máxima, do músculo Longissimus dorsi; medida C - espessura de gordura sobre o músculo Longissimus dorsi: espessura da gordura de cobertura sobre a secção transversal desse músculo, à continuação do eixo B; medida $\mathbf{J}$ - espessura máxima de gordura de cobertura no perfil do lombo.

O lombo da meia-carcaça esquerda foi separado e dissecado para determinação das proporções de músculo, gordura e osso. As amostras do músculo Longissimus dorsi (entre a 12 $2^{\mathrm{a}}$ e 13 ${ }^{\mathrm{a}}$ costelas) foram acondicionadas em embalagens de polietileno e armazenadas a $-18^{\circ} \mathrm{C}$ até o início das análises, quando foram descongeladas até atingirem temperatura ambiente. Em seguida, foram trituradas em processador de alimentos e devidamente homogeneizadas em gral de porcelana. Todas as análises foram realizadas em duplicata utilizando-se o músculo Longissimus dorsi in natura.

As análises de umidade, cinzas e proteína foram realizadas segundo metodologia da AOAC (1980). A extração de lipídios totais foi realizada utilizando-se a técnica a frio descrita por Folch et al. (1957), com solução de clorofórmio/ metanol $(2: 1 \mathrm{v} / \mathrm{v})$. Para a transesterificação dos triacilgliceróis, foi utilizado o método 5509 da ISO (1978), em solução de n-heptano e KOH/metanol

Os ésteres de ácidos graxos foram isolados e analisados em cromatógrafo gasoso Shimadzu 14A, equipado com detector de ionização de chama e coluna capilar de sílica fundida ( $50 \mathrm{~m}$ de comprimento, $0,25 \mathrm{~mm}$ de diâmetro interno e $0,20 \mu \mathrm{m}$ de Carbowax 20M). Os fluxos dos gases foram de $1,2 \mathrm{~mL} / \mathrm{min}$ para o gás de arraste $\left(\mathrm{H}_{2}\right) ; 30 \mathrm{~mL} / \mathrm{min}$ para o gás auxiliar $\left(\mathrm{N}_{2}\right)$ e 30 e $300 \mathrm{~mL} / \mathrm{min}$ para o $\mathrm{H}_{2}$ e o ar sintético, respectivamente. A temperatura inicial para a chama da coluna foi estabelecida em $150^{\circ} \mathrm{C}$, mantida por 3 minutos, sendo então elevada para $240^{\circ} \mathrm{C}$ a uma taxa de $10^{\circ} \mathrm{C} / \mathrm{min}$. A razão de divisão da amostra foi de 1:100. As áreas dos picos foram determinadas utilizando-se Integrador-Processador CG-300. A identificação dos picos foi feita por comparação dos tempos de retenção aos padrões de ésteres metílicos de ácidos graxos da Sigma ${ }^{\circledR}$.

A extração e a quantificação de colesterol foram feitas segundo o método descrito por Al-Hasani et al. (1993). O teor de colesterol foi quantificado por meio do cromatógrafo a gás Shimadzu 14A, equipado com detector de ionização de chama e coluna capilar de sílica fundida ( $25 \mathrm{~m}$ de comprimento, $0,25 \mathrm{~mm}$ de diâmetro interno e $0,20 \mu \mathrm{m}$ de SE-30). As temperaturas do injetor, da coluna e do detector foram 260 , 300 e $300^{\circ} \mathrm{C}$, respectivamente. Os fluxos de gases foram: $1,5 \mathrm{~mL} / \mathrm{min}$ para o gás de arraste $\left(\mathrm{H}_{2}\right) ; 25 \mathrm{~mL} / \mathrm{min}$ para o gás de reposição $\left(\mathrm{N}_{2}\right)$ e para a chama; $300 \mathrm{~mL} / \mathrm{min}$ para o ar sintético e $30 \mathrm{~mL} / \mathrm{min}$ para o $\mathrm{H}_{2}$. A razão de divisão da 
amostra foi de 1:150. A integração dos picos foi realizada com o Integrador-Processador CG-300. A identificação do colesterol foi feita por comparação aos padrões da Sigma ${ }^{\circledR}$ e a quantificação do colesterol contido na amostra foi realizada após a verificação da linearidade do método, sendo preparadas e analisadas soluções de colesterol padrão com concentrações 0,$10 ; 0,25 ; 0,50 \mathrm{e} 1,00 \mathrm{mg} / \mathrm{mL}$, todas contendo $0,20 \mathrm{mg} / \mathrm{mL}$ de $5 \alpha$-colestano (padrão interno), sendo então plotado um gráfico da razão entre as áreas obtidas e a concentração de colesterol.

A análise estatística foi realizada utilizando-se o programa SAEG (Sistema para Análises Estatísticas e Genéticas), desenvolvido pela Universidade Federal de Viçosa (UFV, 1997), de acordo com o seguinte modelo:

$$
\mathrm{Y}_{\mathrm{ij}}=\mu+\mathrm{T}_{\mathrm{i}}+\mathrm{e}_{\mathrm{ij}}
$$

em que: $Y_{i j}=$ observação da variável estudada no animal $j$, recebendo o tratamento $\mathrm{i} ; \mu=$ constante geral; $\mathrm{T}_{\mathrm{i}}=$ efeito do tratamento i; i = 0, 50 e $100 \%$ de casca do grão de soja em substituição ao milho; $\mathrm{e}_{\mathrm{ij}}=$ erro aleatório associado a cada observação $Y_{\mathrm{ij}}$.

\section{Resultados e Discussão}

As características de carcaças avaliadas não diferiram $(\mathrm{P}>0,05)$ entre os tratamentos (Tabela 3 ). $\mathrm{O}$ valor da perda por resfriamento $(5,44 \%)$ foi superior ao obtido em estudos com animais Saanen e Boer x Saanen (Ulhoa, 2001; Pereira Filho, 2003; Silva, 2005) abatidos com pesos similares ao deste experimento ( $3,05 \%$, em média).
Os valores obtidos para os rendimentos verdadeiro (RVC) e comercial de carcaça (RCC) não foram influenciados $(\mathrm{P}>0,05)$ pelos tratamentos e mantiveram-se na faixa aceitável para caprinos. Estudos avaliando animais Boer e seus cruzamentos (Cameron et al., 2001; Moore et al., 2002; Dhanda et al., 2003a; Sheridan et al., 2003; Pereira Filho, 2003; Silva, 2005) têm apresentado valores de RVC e RCC de 50,60 a $57,69 \%$ e de 37,90 a $48,80 \%$, respectivamente.

Zundt et al. (2001) e Grande et al. (2003) observaram valores médios de 0,17 e $0,38 \mathrm{~kg} / \mathrm{cm}$ para os índices de compacidade da carcaça (ICC) e da perna (ICP), respectivamente, em cabritos Saanen. Avaliando diferentes níveis energéticos $(2,15 ; 2,39 ; 2,63$ e 2,87 Mcal EM/kg MS) em dietas para cabritos Boer x Saanen, Silva (2005) observou efeito linear para ICC $(\mathrm{Y}=-0,009+0,020 \mathrm{X}), \mathrm{ICP}(\mathrm{Y}=0,345+0,005 \mathrm{X})$ e conformação $(\mathrm{CO})(\mathrm{Y}=0,708+0,246 \mathrm{X})$. Estas diferenças observadas para os índices de compacidade podem estar relacionadas à idade e ao peso corporal ao abate, assim como à raça caprina utilizada nos experimentos.

A cobertura de gordura ( $\mathrm{CBG})$ das carcaças não diferiu $(\mathrm{P}>0,05)$ entre os tratamentos (média de 3,04). $\mathrm{O}$ rendimento de cortes comerciais, no entanto, foi influenciado $(\mathrm{P}<0,05)$ pelos tratamentos, de modo que os animais alimentados com a ração CGS50 apresentaram maior rendimento de lombo e aqueles do tratamento CGS100, maior proporção de pescoço (Tabela 4).

Estudos com animais cruzados Boer têm demonstrado rendimentos de 5,56 a $9,88 \%$ de lombo e de 6,74 a $7,94 \%$ de pescoço (Cameron et al., 2001; Selaive-Villarroel et al., 2004;

Tabela 3 - Peso corporal ao abate (PCA), peso de carcaça quente (PCQ), peso de carcaça fria (PCF), rendimentos verdadeiro (RVC) e comercial (RCC) da carcaça, perda por resfriamento (PPR), índice de compacidade da carcaça (ICC) e da perna (ICP), conformação $(C O)$ e cobertura de gordura (CBG) de cabritos mestiços recebendo rações com casca do grão de soja em substituição ao milho

Table 3 - Means and coefficient of variation for slaughter body weight (SBW), hot carcass weight (HCW), cold carcass weight (CCW), weight loss by cooling (WLC), carcass yield (CY), carcass biological yield (CBY), carcass compacity index (CCI), leg compacity index (LCI), conformation (CO) and fat covering $(F C)$ of crossbred Boer $x$ Saanen kids fed diets with increasing levels of soybean hulls

\begin{tabular}{|c|c|c|c|c|c|}
\hline \multirow[t]{2}{*}{$\begin{array}{l}\text { Característica } \\
\text { Item }\end{array}$} & \multicolumn{3}{|c|}{$\begin{array}{c}\text { Tratamento } \\
\text { Treatment }\end{array}$} & \multirow[t]{2}{*}{$\begin{array}{l}\text { Média } \\
\text { Mean }\end{array}$} & \multirow[t]{2}{*}{$\mathrm{CV}(\%)$} \\
\hline & $\begin{array}{c}\mathrm{GMM}_{(\mathrm{n}=4)} \\
\quad G C G\end{array}$ & $\begin{array}{c}\text { CGS } 50(\mathrm{n}=5) \\
\text { SH } 50\end{array}$ & $\begin{array}{c}\text { CGS } 100(\mathrm{n}=5) \\
\text { SH } 100\end{array}$ & & \\
\hline PCA $(\mathrm{kg})(B W, k g)$ & 35,53 & 34,03 & 31,89 & 33,82 & 13,31 \\
\hline PCQ $(\mathrm{kg})(H C W, k g)$ & 17,77 & 17,64 & 15,84 & 17,08 & 12,19 \\
\hline PCF $(\mathrm{kg})(C C W, k g)$ & 16,88 & 16,58 & 15,02 & 16,16 & 12,92 \\
\hline PPR (\%) (WLC, \%) & 5,01 & 6,11 & 5,21 & 5,44 & 34,83 \\
\hline $\operatorname{RVC}(\%)(C Y, \%)$ & 57,25 & 57,71 & 55,79 & 56,91 & 4,38 \\
\hline $\operatorname{RCC}(\%)(C B Y, \%)$ & 47,60 & 48,78 & 47,06 & 47,81 & 2,89 \\
\hline ICC $(\mathrm{kg} / \mathrm{cm})(C C I, \mathrm{~kg} / \mathrm{cm})$ & 0,25 & 0,26 & 0,24 & 0,25 & 12,00 \\
\hline $\mathrm{ICP}(L C I)$ & 0,40 & 0,35 & 0,36 & 0,37 & 7,48 \\
\hline $\mathrm{CO}(\mathrm{CO})$ & 3,13 & 3,10 & 3,10 & 3,11 & 14,02 \\
\hline $\mathrm{CBG}(F C)$ & 3,13 & 3,00 & 3,00 & 3,04 & 12,90 \\
\hline
\end{tabular}

${ }^{1}$ GMM - grão de milho moído, CGS 50 - 50\% de casca do grão de soja em substituição ao milho moído, CGS 100 - $100 \%$ de casca do grão de soja em substituição ao milho moído.

${ }^{1}$ GCG - ground corn grain, SH 50-50\% of soybean hulls replacing ground corn grain, SH $100-100 \%$ of soybean hulls replacing ground corn grain. 
Tabela 4 - Rendimentos dos cortes comerciais de cabritos mestiços alimentados com rações formuladas com diferentes níveis de substituição do milho por casca do grão de soja

Table 4 - Means and coefficient of variation for retail cuts of crossbred Boer $x$ Saanen kids fed diets with increasing levels of soybean hulls

\begin{tabular}{|c|c|c|c|c|}
\hline \multirow{2}{*}{$\begin{array}{l}\text { Corte } \\
\text { Cut }\end{array}$} & \multicolumn{3}{|c|}{$\begin{array}{c}\text { Tratamento } \\
\text { Treatment }\end{array}$} & \multirow[t]{2}{*}{$\mathrm{CV}(\%)$} \\
\hline & $\begin{array}{c}\operatorname{GMM}_{(\mathrm{n}=4)} \\
\quad G C G\end{array}$ & $\begin{array}{c}\text { CGS } 50(\mathrm{n}=5) \\
\text { SH } 50\end{array}$ & $\begin{array}{c}\text { CGS } 100(\mathrm{n}=5) \\
\quad \text { SH } 100\end{array}$ & \\
\hline Pescoço (Neck) & $7,11 \mathrm{~b}$ & $7,37 \mathrm{ab}$ & $8,97 \mathrm{a}$ & 12,32 \\
\hline Costela (Rib) & 8,52 & 8,33 & 8,00 & 11,63 \\
\hline Costela descoberta (Ribs under the shoulder) & 13,83 & 13,19 & 12,79 & 10,22 \\
\hline Paleta (Shoulder) & 21,09 & 21,52 & 20,84 & 5,87 \\
\hline Baixos (Breast and rib points) & 11,94 & 10,31 & 11,00 & 11,31 \\
\hline Lombo (Loin) & $7,14 \mathrm{~b}$ & $8,71 \mathrm{a}$ & $8,05 \mathrm{ab}$ & 8,15 \\
\hline Perna (Leg) & 29,74 & 30,70 & 30,26 & 3,40 \\
\hline
\end{tabular}

1 GMM - grão de milho moído, CGS 50 - 50\% de casca do grão de soja em substituição ao milho moído, CGS 100 - 100\% de casca do grão de soja em substituição ao milho moído.

Médias acompanhadas de letras diferentes na mesma linha diferem $(\mathrm{P}<0,05)$ pelo teste Tukey.

${ }^{1}$ GCG - ground corn grain, SH 50-50\% of soybean hulls replacing ground corn grain, SH $100-100 \%$ of soybean hulls replacing ground corn grain .

Means followed by different letters in a row differ $(P<0.05)$ by Tukey test.

Tabela 5 - Médias e coeficientes de variação para área de olho-de-lombo (AOL), comprimento maior (medida A), comprimento menor (medida B), espessura de gordura (medida $\mathrm{C}$ ), espessura maior de gordura (medida J) e porcentagens de músculo, gordura e osso do lombo de cabritos mestiços alimentados com rações formuladas com diferentes níveis de substituição do milho por casca do grão de soja

Table 5 - $\quad$ Means and coefficient of variation for loin area ( $L A)$, large length (measure A), short length (measure B), fat thickness (measure C), large fat thickness (measure J), and proportions of muscle, fat and bone of the loin of crossbred Boer $x$ Saanen kids fed diets with increasing levels of soybean hulls

\begin{tabular}{|c|c|c|c|c|c|}
\hline \multirow[t]{2}{*}{$\begin{array}{l}\text { Parâmetro } \\
\text { Item }\end{array}$} & \multicolumn{3}{|c|}{$\begin{array}{c}\text { Tratamento }^{1} \\
\text { Treatment }\end{array}$} & \multirow[t]{2}{*}{$\begin{array}{l}\text { Média } \\
\text { Mean }\end{array}$} & \multirow[t]{2}{*}{$\mathrm{CV}(\%)$} \\
\hline & $\begin{array}{c}\mathrm{GMM}_{(\mathrm{n}=4)} \\
\quad G C G\end{array}$ & $\begin{array}{c}\text { CGS } 50(\mathrm{n}=5) \\
\text { SH } 50\end{array}$ & $\begin{array}{c}\text { CGS } 100(\mathrm{n}=5) \\
\quad S H 100\end{array}$ & & \\
\hline AOL $\left(\mathrm{cm}^{2}\right)\left(L A, \mathrm{~cm}^{2}\right)$ & 15,21 & 14,41 & 12,25 & 13,96 & 15,70 \\
\hline Medida A $(\mathrm{mm})$ (Measure A, $\mathrm{mm}$ ) & 53,10 & 54,64 & 50,28 & 52,67 & 10,58 \\
\hline Medida B $(\mathrm{mm})$ (Measure $B, \mathrm{~mm}$ ) & 26,30 & 26,38 & 21,56 & 24,75 & 14,98 \\
\hline Medida $\mathrm{C}(\mathrm{mm})$ (Measure $C, \mathrm{~mm}$ ) & 1,55 & 1,30 & 1,50 & 1,45 & 57,34 \\
\hline Medida $\mathrm{J}(\mathrm{mm})$ (Measure $\mathrm{J}, \mathrm{mm}$ ) & 3,07 & 2,42 & 2,78 & 2,76 & 43,95 \\
\hline Músculo (\%) (Muscle, \%) & 72,64 & 68,05 & 70,25 & 70,31 & 5,73 \\
\hline Gordura $(\%)(F a t, \%)$ & $16,79 \mathrm{a}$ & $14,94 a b$ & $10,07 \mathrm{~b}$ & - & 21,92 \\
\hline Osso (\%) (Bone, \%) & $10,57 \mathrm{~b}$ & $17,01 \mathrm{ab}$ & $19,68 \mathrm{~b}$ & - & 25,12 \\
\hline
\end{tabular}

${ }^{1}$ GMM - grão de milho moído, CGS 50 - 50\% de casca do grão de soja em substituição ao milho moído, CGS 100 - 100\% de casca do grão de soja em substituição ao milho moído.

Médias acompanhadas de letras diferentes na mesma linha diferem $(\mathrm{P}<0,05)$ pelo teste Tukey.

${ }^{1}$ GCG - ground corn grain, SH 50-50\% of soybean hulls replacing ground corn grain, SH $100-100 \%$ of soybean hulls replacing ground corn grain

Means followed by different letters in a row differ $(P<0.05)$ by Tukey test.

Silva, 2005), enquanto, para a raça Saanen, foram observados valores de 8,49 a 11,50\% e de 5,91 a 9,30\% para rendimentos de lombo e pescoço, respectivamente (Ulhoa, 2001; Yáñez, 2002; Grande et al., 2003). Esta diferença de resultados pode estar relacionada às diferenças de idade e de peso corporal ao abate.

O rendimento dos demais cortes comerciais não foi afetado $(\mathrm{P}>0,05)$ pelos tratamentos, sendo obtidas médias de $30,23 \%$ para perna, $21,15 \%$ para paleta, $8,28 \%$ para costela, $13,27 \%$ para costela descoberta e $11,08 \%$ para baixos, próximas àquelas encontradas em animais Saanen (Ulhoa, 2001; Yáñez, 2002; Grande et al., 2003) e cruzados
Boer (Cameron et al., 2001; Pereira Filho, 2003; SelaiveVillarroel et al., 2004; Silva, 2005).

As características avaliadas no músculo Longissimus dorsi não diferiram $(\mathrm{P}>0,05)$ entre os tratamentos (Tabela 5). Os resultados obtidos para a área de olho-delombo (AOL) e espessura de gordura (medida $\mathrm{C}$ ) foram próximos aos observados na literatura, de 10,42 a $18,02 \mathrm{~cm}^{2}$ e de 0,79 a 1,8 mm, respectivamente (Dhanda et al., 2003a; Cameron et al., 2001; Oman et al., 2000; Silva, 2005).

Os comprimentos maior e menor do músculo Longissimus dorsi servem para avaliação da quantidade de músculo na carcaça e são significativamente 
correlacionados à área de olho-de-lombo e à conformação. Resultados semelhantes aos observados neste trabalho foram obtidos por Kadim et al. (2003) em cabritos cruzados Omani ( $\pm 30 \mathrm{~kg}$ de PV), médias de 57,67 mm de comprimento maior e de 27,67 mm de comprimento menor do músculo.

A proporção de músculo do Longissimus dorsi não diferiu $(\mathrm{P}>0,05)$ entre os tratamentos, apresentando média de 70,31\%. Resultados semelhantes foram observados por Pereira Filho (2003) e Silva (2005) em cabritos Boer x Saanen e por Yáñez (2002), em animais Saanen.

A substituição do milho pela casca do grão de soja nas rações reduziu $(\mathrm{P}<0,05)$ a proporção de gordura, resultando em aumento na porcentagem de osso, visto que os teores de músculo não variaram entre os tratamentos. A menor proporção de gordura observada pode ser resultado da energia gerada em decorrência da substituição. Ainda, a casca do grão de soja na fermentação ruminal incrementa a produção de acetato, resultando em redução de síntese de gordura corporal (Moe, 1981), se comparada ao milho.

A composição centesimal do músculo Longissimus dorsi não foi influenciada $(\mathrm{P}>0,05)$ pela substituição do milho pela casca do grão de soja, sendo registradas médias de $75,06 \%$ para umidade, 20,49\% para proteína, 2,98\% para lipídios totais e $0,97 \%$ para cinzas (Tabela 6).

Para alguns parâmetros avaliados, foram verificados coeficientes de variação elevados, o que, provavelmente, foi ocasionado pelo número de animais utilizados no experimento.

Os valores de umidade, proteína e cinzas foram próximos àqueles apresentados na literatura (Dhanda et al., 1999, 2003b; Madruga et al., 1999, 2001; Beserra et al., 2000, 2004; Silva, 2005) e variam de 70,80 a 80,25\%, de 18,50 a $23,39 \%$ e de 0,79 a $1,68 \%$, respectivamente.

A substituição do milho pela casca de soja nas rações promoveu aumento $(\mathrm{P}<0,05)$ de 36,39 para 47,67 mg/100 g no teor de colesterol da carne caprina, entretanto, esses valores estão dentro da faixa descrita por Beserra et al. (2004), que, em estudo com animais alimentados com pastagem nativa suplementada com capim-elefante e silagem de sorgo, observaram valores de 20,5 e 71,4 mg/100 g de colesterol, nos animais abatidos com 4 a 6 e 8 a 10 meses de idade, respectivamente.

Madruga et al. (2001) observaram que a carne de animais castrados possui maior $(\mathrm{P}<0,05)$ teor de colesterol

Tabela 6 - Composição centesimal e perfil de ácidos graxos do músculo Longissimus dorsi de cabritos mestiços alimentados com rações formuladas com diferentes níveis de substituição do milho por casca do grão de soja

Table 6 - Chemical composition and fatty acid profile of the Longissimus dorsi muscle of Boer $x$ Saanen kids fed diets with increasing levels of soybean hulls

\begin{tabular}{|c|c|c|c|c|}
\hline \multirow[t]{2}{*}{$\begin{array}{l}\text { Característica } \\
\text { Item }\end{array}$} & \multicolumn{3}{|c|}{$\begin{array}{c}\text { Tratamento } \\
\text { Treatment }\end{array}$} & \multirow[t]{2}{*}{$\mathrm{CV}(\%)$} \\
\hline & $\begin{array}{c}\operatorname{GMM}_{(\mathrm{n}=4)} \\
G C G\end{array}$ & $\begin{array}{c}\text { CGS } 50 \\
\text { SH } 50\end{array}$ & $\begin{array}{c}\text { CGS } 100(\mathrm{n}=5) \\
\text { SH } 100^{-}\end{array}$ & \\
\hline Umidade (\%) (Moisture) & 74,10 & 76,01 & 75,06 & 2,20 \\
\hline Proteína $(\%)$ (Protein) & 20,73 & 19,98 & 20,77 & 6,16 \\
\hline Lipídios totais (\%) (Total lipids) & 3,29 & 2,87 & 2,77 & 33,83 \\
\hline Cinzas $(\%)($ Ash $)$ & 0,98 & 0,92 & 1,02 & 11,91 \\
\hline Colesterol (mg/100 g) (Cholesterol) & $36,39 b$ & $44,52 \mathrm{a}$ & $47,67 \mathrm{a}$ & 9,80 \\
\hline \multicolumn{5}{|l|}{ Ácido $\operatorname{graxo}^{1}(\%)$ (Fatty acid, \%) } \\
\hline C14:0 (mirístico) (miristic) & 1,37 & 1,20 & 1,53 & 37,06 \\
\hline C16:0 (palmítico) (palmitic) & 22,90 & 18,57 & 18,59 & 21,64 \\
\hline C16:1n-7 (palmitoléico) (palmitoleic) & 1,40 & 1,24 & 0,99 & 22,46 \\
\hline C17:0 (margárico) (margaric) & 1,26 & 1,02 & 0,96 & 33,19 \\
\hline C18:0 (esteárico) (stearic) & 11,88 & 15,38 & 16,43 & 25,07 \\
\hline C18:1n-9 (oléico) (oleic) & 40,02 & 42,90 & 34,97 & 14,09 \\
\hline C18:2n-6 (linoléico) (linoleic) & 3,16 & 8,11 & 12,78 & 60,05 \\
\hline C20:4n-6 (araquidônico) (arachidonic) & 2,92 & 1,64 & 2,74 & 42,02 \\
\hline AGPI (PUFA) & 14,33 & 14,10 & 20,10 & 41,13 \\
\hline AGMI (MUFA) & 45,35 & 47,48 & 39,23 & 12,09 \\
\hline AGS (SFA) & 40,32 & 38,42 & 40,67 & 14,22 \\
\hline AGPI/AGS (PUFA/AGS) & 0,37 & 0,40 & 0,51 & 53,71 \\
\hline
\end{tabular}

1 GMM - grão de milho moído, CGS 50 - 50\% de casca do grão de soja em substituição ao milho moído, CGS 100 - $100 \%$ de casca do grão de soja em substituição ao milho moído.

$2 \mathrm{AGPI}=$ ácidos graxos poliinsaturados, AGMI = ácidos graxos monoinsaturados, AGS = ácidos graxos saturados .

Médias acompanhadas de letras diferentes na mesma linha diferem $(P<0,05)$ pelo teste Tukey.

1 GCG-ground corn grain, SH 50-50\% of soybean hulls replacing ground corn grain, SH 100-100\% of soybean hulls replacing ground corn grain.

2 PUFA = polyunsatured fatty acid, MUFA = monounsatured fatty acid, SFA = satured fatty acid

Means followed by different letters in a row differ $(P<0.05)$ by Tukey test. 
(62,5 vs $58,0 \mathrm{mg} / 100 \mathrm{~g}$ para não-castrados). Do mesmo modo, a carne de animais abatidos com 175 e 310 dias de idade apresentou, respectivamente, 57,5 e $74,1 \mathrm{mg}$ de colesterol/100 g. Esta variação da concentração de colesterol pode estar relacionada à metodologia utilizada na determinação, ao tipo de músculo analisado e aos fatores idade de abate e castração.

Outro fator que pode ter contribuído para esta diferença é o perfil de ácidos graxos dos alimentos utilizados. O milho apresentou 13,51\% de ácido palmítico (C16:0), 2,30\% ácido esteárico (C18:0) e 33,58\% de ácido oléico (C18:1), enquanto a casca de soja, 16,05\% de C16:0, 6,12\% de C18:0 e 18,57\% de C18:1. Sabe-se que a concentração plasmática de colesterol é influenciada pela composição de ácidos graxos da dieta: o C16:0 aumenta, enquanto o C18:1 diminui e o C18:0 não exerce nenhuma influência sobre o nível de colesterol sanguíneo (Madruga, 2004).

A concentração dos ácidos graxos saturados C14:0 (ácido mirístico), C16:0, C17:0 (ácido margárico) e C18:0 não foi influenciada $(\mathrm{P}>0,05)$ pela substituição do milho pela casca do grão de soja na ração. Os valores médios obtidos de 1,$37 ; 20,02 ; 1,08$ e 14,56\%; respectivamente foram próximos aos observados por Madruga et al. (2001), Beserra et al. (2004), Rhee et al. (2000) e Santos-Filho et al. (2005) em trabalhos com caprinos.

Apesar da ausência de diferença $(\mathrm{P}>0,05)$, houve aumento de 3,16 para $12,78 \%$, na concentração do ácido linoléico (C18:2) e diminuição de 40,02 para 34,97\% na concentração do C18:1 nos animais que receberam rações com casca do grão de soja. Comportamento similar no perfil destes ácidos graxos também foi observado por Rhee et al. (2000), ao compararem a carne de cabritos alimentados com ração concentrada (67,5\% de grão de sorgo, $12,0 \%$ de casca do caroço de algodão, $5,0 \%$ de feno de alfafa triturada, $4 \%$ de farelo de algodão, $4 \%$ de farelo de soja, $4 \%$ de melado, minerais e vitaminas) a cabritos em pastagem nativa. Os resultados foram semelhantes ainda aos obtidos por Resosemito (2003), em experimento com cabritos em confinamento e em pastagem.

Os teores dos ácidos palmitoléico (C16:1) e araquidônico ( $\mathrm{C} 20: 4)$ não diferiram $(\mathrm{P}>0,05)$ entre os tratamentos (médias de 1,21 e 2,43\%, respectivamente).

A carne caprina apresentou maiores teores de ácidos graxos monoinsaturados (AGMI) $(44,02 \%)$, seguidos dos saturados (AGS) $(39,80 \%)$ e dos poliinsaturados (AGPI) $(16,18 \%)$, que não diferiram $(\mathrm{P}>0,05)$ entre os tratamentos. A relação AGPI/AGS foi de 0,42 e está de acordo com a recomendação do Department of Healt - UK, de 0,40 (Wood et al., 2003).
Dhanda et al. (1999), trabalhando com animais Boer x Saanen com diferentes pesos de abate, obtiveram valores de 0,05 e 0,15 para a relação AGPI/AGS. Madruga et al. (2001) observaram relação de 0,11 na carne de animais mestiços abatidos com 175 dias de idade, enquanto Rhee et al. (2000), comparando cabritos Boer x Spanish alimentados em pastagem ou com ração à base de grãos, verificaram relações de 0,23 e 0,30 , respectivamente. Silva (2005), utilizando diferentes níveis de energia em rações para cabritos, observou relações AGPI/AGS de 0,15 a 0,32.

\section{Conclusões}

A substituição do milho pela casca do grão de soja em rações para cabritos não altera as características das carcaças e o perfil dos ácidos graxos da carne.

\section{Agradecimento}

À Cooperativa Agroindustrial de Maringá - COCAMAR, pelo apoio à pesquisa e pela doação da casca do grão de soja, imprescindível para a realização deste trabalho.

\section{Literatura Citada}

AL-HASANI, S.M.; HLAVAC, J.; CARPENTER, M.W. Rapid determination of cholesterol in single and multicomponent prepared foods. Journal of the Association Official Analytical Chemists International, v.76, p.902-906, 1993.

ASSOCIATION OF OFFICIAL ANALITICAL CHEMISTIS - AOAC. Official methods of analysis. 14.ed. Arlington: AOAC, 1980. $1094 \mathrm{p}$.

BANSKALIEVA, V.; SAHLU, T.; GOETSCH, A.L. Fatty acid composition of goat muscles and fat depots: a review. Small Ruminant Research, v.37, p.255-268, 2000

BESERRA, F.J.; MONTE, A.L.S.; BEZERRA, L.C.N.M. et al. Caracterização química da carne de cabritos da raça Moxotó e de cruzas Pardo Alpina x Moxotó. Pesquisa Agropecuária Brasileira, v.35, n.1, p.171-177, 2000.

BESERRA, F.J.; MADRUGA, M.S.; LEITE, A.M. et al. Effect of age at slaughter on chemical composition of meat from Moxotó goats and their crosses. Small Ruminant Research, v.55, p. $177-181,2004$.

CAMERON, M.R.; LUO, J.; SAHLU, T. et al. Growth and slaughter traits of Boer x Spanish, Boer x Angora, and Spanish goats consuming a concentrate-based diet. Journal of Animal Science, v.79, p.1423-1430, 2001

COLOMER-ROCHER, F.; MORAND-FEHR, P.; KIRTON, A.H. et al. Metodos normalizados para el estudio de los caracteres cuantitativos $y$ cualitativos de las canales caprinas $y$ ovinas. Madrid: Instituto Nacional de Investigaciones Agrarias, 1988. 41p. (Cuadernos INIA, 17)

DHANDA, J.S.; TAYLOR, D.G.; MURRAY, P.J. et al. The influence of goat genotype on the production of Capretto and Chevon carcasses. 4. Chemical composition of muscle and fatty acid profiles of adipose tissue. Meat Science, v.52, p.375-379, 1999.

DHANDA, J.S.; TAYLOR, D.G.; MURRAY, P.J. Part 1. Growth, carcass and meat quality parameters of male goats: effects of 
genotype and liveweight at slaughter. Small Ruminant Research, v.50, p.57-66, 2003a.

DHANDA, J.S.; TAYLOR, D.G.; MURRAY, P.J. Part 2. Carcass composition and fatty acid profiles of adipose tissue of male goats: effects of genotype and liveweight at slaughter. Small Ruminant Research, v.50, p.67-74, 2003b.

FOLCH, J.; LESS, M.; SLOANE, S.G.H. A simple method for the isolation and purification of total lipids from animal tissues. The Journal of Biological Chemistry, v.226, n.1, p.497$509,1957$.

GRANDE, P.A.; ALCALDE, C.R.; MACEDO, F.A.F. et al. Desempenho e características de carcaça de cabritos da raça Saanen recebendo rações com farelo de glúten de milho e/ou farelo de soja. Acta Scientiarum, v.25, n.2, p.315-321, 2003.

INTERNATIONAL ORGANIZATION FOR STANDARDIZATION - ISO. Animal and vegetable fats and oils - Preparation of methyl esters of fatty acids (Method ISO 5509). Geneve: ISO, 1978. p.1-6.

KADIM, I.T.; MAHGOUB, O.; AL-AJMI, D.S. et al. An evaluation of the growth, carcass and meat quality characteristics of Omani goat breeds. Meat Science, v.66, p.203-210, 2003.

MADRUGA, M.S.; ARRUDA, S.G.B.; NASCIMENTO, J.A. Castration and slaughter age effects on nutritive value of the "Mestiço" goat meat. Meat Science, v.52, p.119-125, 1999.

MADRUGA, M.S.; NARAIN, N.; SOUZA, J.G. et al. Castration and slaughter age effects on fat components of "Mestiço" goat meat. Small Ruminant Research, v.42, p.77-82, 2001.

MADRUGA, M.S.; SOUZA, J.G.; ARRUDA, S.G.B. et al. Carne caprina de animais mestiços: Estudos do perfil aromático. Ciência e Tecnologia de Alimentos, v.23, n.3, p.323-329, 2003.

MADRUGA, M.S. Qualidade química, sensorial e aromática da carne caprina: mitos e verdades. In: ENCONTRO NACIONAL PARA O DESENVOLVIMENTO DA ESPÉCIE CAPRINA, 8., 2004, Botucatu. Anais... Botucatu: UNESP/FMVZ, 2004. p.233.

MALAN, S.W. The improved Boer goat. Small Ruminant Research, v.36, p.165-170, 2000.

MOE, P.W. Energy metabolism of dairy cattle. Journal Dairy Science, v.64, p.1120-1139, 1981

MOORE, J.A.; POORE, M.H.; LUGINBUHL, J.M. By-product feeds for meat goats: Effects on digestibility, ruminal environment, and carcass characteristics. Journal of Animal Science, v.80, p.1752-1758, 2002.

MOTTRAM, D.S. Flavour formation in meat and meat products: a review. Food Chemistry, v.62, n.4, p.415-424, 1998.

NAUDÉ, R.T.; HOFMEYR, H.S. Meat production. In: GALL, C. (Ed.) Goat production. London: Academic Press, 1981. p.285-307.

OMAN, J.S.; WALDRON, D.F.; GRIFFIN, D.B.et al. Carcass traits and retail display-life of chops from different goat breed types. Journal of Animal Science, v.78, p.1262-1266, 2000.

PEREIRA FILHO, J.M. Estudo do crescimento alométrico e das características de carcaça e impacto econômico da restrição alimentar de cabritos $F 1$ Boer $x$ Saanen. Jaboticabal: Universidade Estadual Paulista, 2003. 85p. Tese (Doutorado em Zootecnia) - Universidade Estadual Paulista, 2003.

POTCHOIBA, M.J.; LU, C.D.; PINKERTON, F. et al. Effects of all-milk diet on weight gain, organ development, carcass characteristics and tissue composition, including fatty acids and cholesterol contents, of growing male goats. Small Ruminant Research, v.3, p.583-592, 1990.

RESOSEMITO, F.S. Composição química de músculos da carne caprina de diferentes genótipos e sistemas de criação. João Pessoa: Universidade Federal da Paraíba, 2003. 69p. Dissertação (Mestrado em Ciência e Tecnologia de Alimentos) - Universidade Federal da Paraíba, 2003.
RHEE, K.S.; WALDRON, D.F.; ZIPRIN, Y.A. et al. Fatty acid composition of goat diets vs intramuscular fat. Meat Science, v.54, p.313-318, 2000.

SAINZ, R.D. Qualidade das carcaças e da carne ovina e caprina. In: REUNIÃO ANUAL DA SOCIEDADE BRASILEIRA DE ZOOTECNIA, 32., 1996, Fortaleza. Anais... Fortaleza: Sociedade Brasileira de Zootecnia, 1996. p.3-14.

SANTOS-FILHO, J.M.; MORAIS, S.M.; RONDINA, D. et al. Effect of cashew nut supplemented diet, castration, and time of storage on fatty acid composition and cholesterol content of goat meat. Small Ruminant Research, v.57, p.51-56, 2005.

SAÑUDO, C.; SIERRA, I. Calidad de la canal en la especie ovina. Ovino, v.11, p.127-157, 1986.

SELAIVE-VILLARROEL, A.B.; MONTE, A.L.S.; OLIVEIRA, A.N. et al. Peso, rendimento de carcaça e cortes comerciais de cabritos mestiços Anglo Nubiana x SRD e Boer x SRD em diferentes graus de sangue. In: REUNIÃO ANUAL DA SOCIEDADE BRASILEIRA DE ZOOTECNIA, 41., 2004, Campo Grande. Anais... Campo Grande: Sociedade Brasileira de Zootecnia, 2004. (CD-ROM).

SHERIDAN, R.; FERREIRA, A.V.; HOFFMAN, L.C. Production efficiency of South African Mutton Merino Lambs and Boer goat kids receiving either a low or a high energy feedlot diet. Small Ruminant Research, v.50, p.75-82, 2003.

SILVA, K.T. Desempenho, digestibilidade e características de carcaças de cabritos mestiços Boer $x$ Saanen confinados, recebendo rações com diferentes níveis energéticos. Maringá: Universidade Estadual de Maringá, 2005. 50p. Dissertação (Mestrado em Zootecnia) - Universidade Estadual de Maringá, 2005.

ULHOA, M.F.P. Desenvolvimento e características de carcaça de caprinos da raça Saanen. Lavras: Universidade Federal de Lavras, 2001. 48p. Dissertação (Mestrado em Zootecnia) Universidade Federal de Lavras, 2001.

UNIVERSIDADE FEDERAL DE VIÇOSA - UFV. SAEG - Sistema para análises estatísticas e genéticas. Versão 7.1. Viçosa, MG: 1997. 150p (Manual do usuário).

WOOD, J.D.; RICHARDSON, R.I.; NUTE, G.R. et al. Effects of fatty acids on meat quality: a review. Meat Science, v.66, p.21-32, 2003

YÁÑEZ, E.A. Desenvolvimento relativo dos tecidos e características da carcaça de cabritos Saanen, com diferentes pesos e níveis nutricionais. Jaboticabal: Universidade Estadual Paulista, 2002. 85p. Tese (Doutorado em Zootecnia) - Universidade Estadual Paulista, 2002.

ZUNDT, M.; MACEDO, F.A.F.; ALCALDE, C.R. et al. Características de carcaça de caprinos alimentados com diferentes níveis energéticos. In: REUNIÃO ANUAL DA SOCIEDADE BRASILEIRA DE ZOOTECNIA, 38., 2001, Piracicaba. Anais... Piracicaba: Sociedade Brasileira de Zootecnia, 2001. (CD-ROM).

ZYGOYIANNIS, D.; KUFIDS, D.; KATSAOUNIS, N. et al. Fatty acid composition of carcass fat of indigenous (Capra prisca) suckled Greek kids and milk of their does. Small Ruminant Research, v.8, p.83-95, 1992. 